\title{
Post-Stapedectomy Granuloma: A Rare Case Report
}

\author{
Kartik Parelkar, Smita Nagle, Mohan Jagade, Poonam Khairnar, Madhavi Pandare, \\ Rajanala Nataraj, Reshma Hanwate, Bandu Nagrale, Devkumar Rangaraja
}

Department of ENT, Grant Govt Medical College \& Sir J J Group of Hospitals, Mumbai, India Email: kartikparelkar@ymail.com

Received 25 May 2015; accepted 30 June 2015; published 3 July 2015

Copyright (C) 2015 by authors and Scientific Research Publishing Inc.

This work is licensed under the Creative Commons Attribution International License (CC BY).

http://creativecommons.org/licenses/by/4.0/

(c) () Open Access

\begin{abstract}
Reparative granuloma in the oval window region is an uncommon complication of stapes surgery, which usually develops within one to eight weeks after operation and causes a sudden hearing loss and disturbance of balance. It may also cause otalgia. Because of its rarity, no single centre would be able to give conclusive evidence regarding this complication. Hence we would like to report our experience and hope to get a better understanding regarding the stapes surgery induced granulation.
\end{abstract}

Keywords

Stapes Surgery, Granulation Tissue, Post-Stapedectomy, Otalgia, Otosclerosis

\section{Introduction}

Since the advent of stapedectomy and its use in the treatment of otosclerosis, a few complications have been reported in the literature. Among them, the granulomatous reaction, described by Harris and Weiss in 1962 [1], is rare. It is an excessive inflammation that forms granulation tissue around the prosthesis and the oval window [2].

The term reparative granuloma is a misnomer [2] as the lesion does not involve granulomatous inflammation and stapes surgery induced granulation tissue is a more appropriate term.

Although the etiology is uncertain, several authors believe that the main cause is a foreign body reaction to the material used in filling the oval window region [3]. Other theories include pyogenic inflammation, autoimmune and allergic reactions or an over exuberant healing process.

The incidence is $0.1 \%$ for stapedectomy and $0.07 \%$ for stapedectomy cases [3]; it generally manifests after surgery as sensorineural dysacusis and vertigo.

It may be confirmed by exploratory tympanotomy to visualize granulation tissue near the prosthesis and the oval window region in a symptomatic patient [3].

How to cite this paper: Parelkar, K., Nagle, S., Jagade, M., Khairnar, P., Pandare, M., Nataraj, R., Hanwate, R., Nagrale, B. and Rangaraja, D. (2015) Post-Stapedectomy Granuloma: A Rare Case Report. International Journal of Otolaryngology and Head \& Neck Surgery, 4, 273-276. http://dx.doi.org/10.4236/ijohns.2015.44046 


\section{Case Report}

A 32-year-old female patient, a known case of unilateral otosclerosis who had undergone left stapedectomy at another institute 6 months back presented with complaints of progressive hearing hearing loss, vertigo and otalgia post-surgery.

Patient had the above complaints 1 to 2 weeks after the stapedectomy, the hearing loss was gradually progressive and constant in nature. While the vertigo had partially subsided with anti-vertiginous drugs, the otalgia affected her daily life. The pain was of throbbing type, over the left post-auricular region, radiating over the temporal region and upper neck on the left side. The symptoms were not relieved by medications. She had no associated ear discharge, tinnitus, facial weakness, nausea or visual complaints.

After ruling out orthopaedic and neuromedical causes for her symptoms a thorough ENT examination was conducted.

On otoscopy bilateral tympanic membranes were intact and hazy. Tympanometery was within normal limits and stapedial reflex was absent on the left side.

Pure tone audiogram (PTA) showed severe to moderate mixed hearing loss in the left ear while the right ear hearing sensitivity was within normal limits. (note: patient did not have sensory component before the stapedotomy; her pre-stapedectomy PTA showed left moderate conductive hearing loss).

High resolution computed tomography (HRCT) of temporal bones showed left ear stapes surgery defect with the piston in situ and in proper position. Minimal soft tissue density at the oval window region near the prosthesis and an partially dehiscent fallopian canal were noted.

After meticulous routine blood investigations and pre-anaesthetic check up an exploratory tympanotomy was scheduled. A written informed consent was taken from the patient.

Procedure was performed under local anaesthesia with intravenous sedation, endomeatal incision was made and the tympanomeatal flap was raised to visualize the middle ear cavity. Exposed facial nerve and the piston in situ were noted, piston was gently removed (Figure 1). A granuloma/granulation tissue was visualized under the over hanging facial nerve on the oval window area where the prosthesis was seated (Figure 2). The granuloma was removed and hemostasis was achieved. Also after removal of the piston necrosed lenticular process of incus was clearly visible (Figure 3).

The tympanomeatal flap was reposited and betadine soaked gelfoam was kept in the external auditory canal. The postoperative period was insignificant. Patient was relieved of otalgia and was started on oral steroids in tapering fashion with antibiotics during the post-op period.

\section{Discussion}

The incidence of reparative granuloma varies from $0.1 \%$ for stapedectomy and $0.07 \%$ for stapedectomy [3]. However certain studies have estimated the incidence up to $1.3 \%$ [4] to $1.8 \%$ [5]. Because of such low incidence rates this complication is rare even for a surgeon who frequently does stapes surgery.

Presenting symptoms usually surface one to eight weeks following surgery and most commonly involve vertigo but may include sensorineural hearing loss, progressive mixed hearing loss, sudden hearing loss and tinnitus [3] [6]. Our patient presented with progressive mixed hearing loss, vertigo and otalgia. Otoscopic findings may be inaccurate and variable as in our case but sometimes dull reddish discolouration in the posterosuperior quadrant of the tympanic membrane or granulations extending into the external auditory canal may also be present.

Reparative granuloma causes hearing impairment in 70 to 100 percent of the cases in early post-stapes surgery period. Vertigo may affect 20 - 35 percent of the cases and sometimes tinnitus, otalgia may also be present $[7]$.

The differential diagnosis is made with perilymphatic fistula and stapedectomy long prosthesis. High resolution computed tomography may be used, since this method makes it possible to identify these conditions [8].

A foreign body reaction has been suggested as the hypothesis, although autoimmune reactions, infection and local inflammation have not been discarded [1]. The most common filling materials in stapedectomy that have been associated with granuloma are blood and gelfoam; in stapedectomy, these materials are fat and gelfoam [3].

They are used to fill in the oval window and to decrease the risk of a perilymphatic fistula. An animal experimental model showed that gelfoam placed in the open oval window niche caused injury to the basilar membrane on histology [9]. 


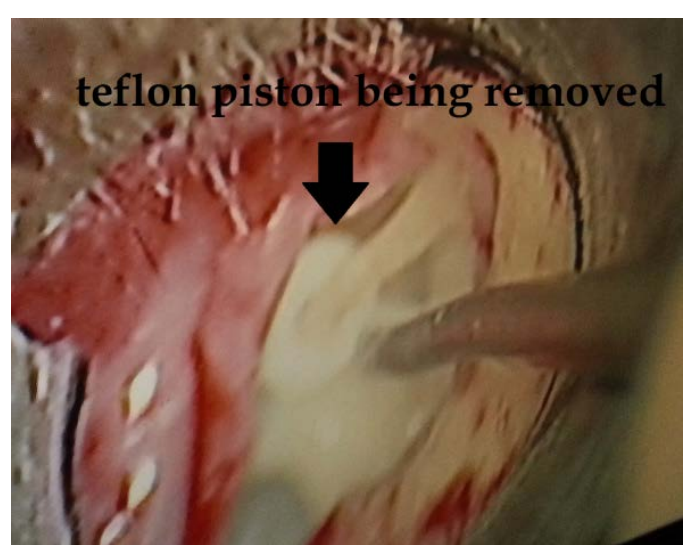

Figure 1. Piston removal.

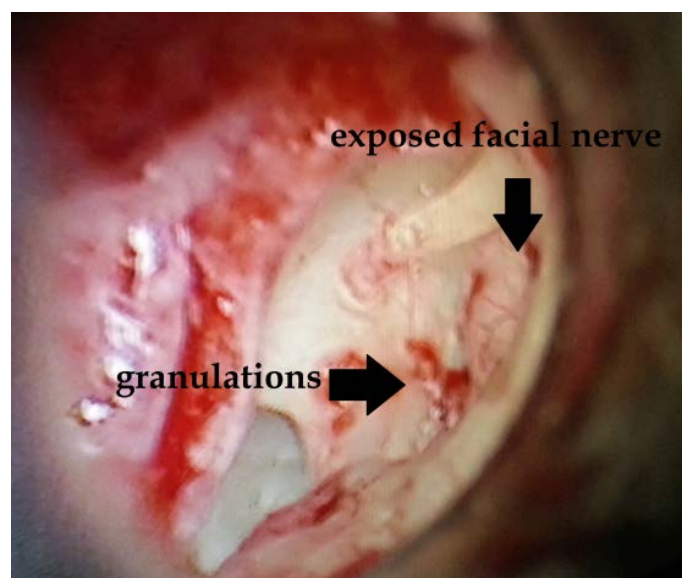

Figure 2. Granuloma.

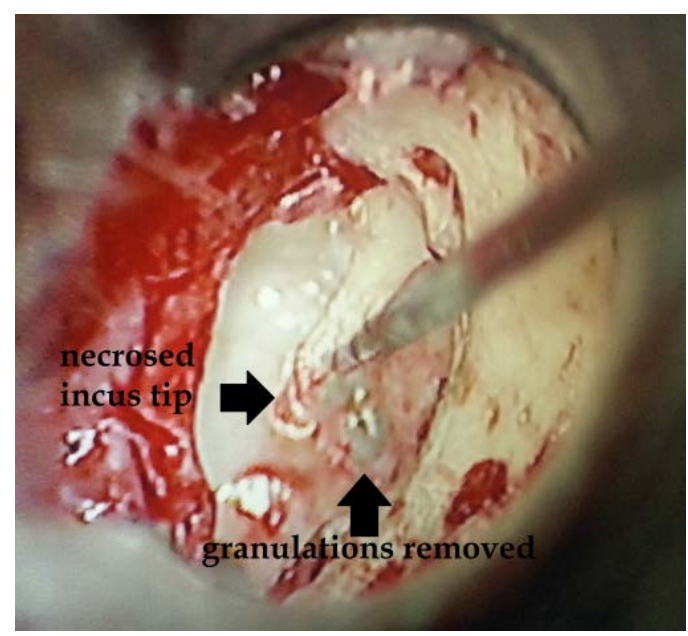

Figure 3. After removal.

Accidental foreign bodies including cotton wool fibers, linen fibers from drapes, glove powder (talc or starch) [10] and fractured Teflon fragments have been considered to stimulate foreign body granuloma. However, Kaufman et al. [6] and Buntner et al. [5] found these materials to be non-contributory.

Though in our case granulations weren't sent for investigation, if frank granulations are present, a bacterial culture along with histopathological reporting is advisable. 
In our case we presume that the friction between teflon piston and the nerve sheath of the exposed facial nerve could have induced the granulation tissue formation.

There is disagreement regarding the mode of management of reparative granuloma. While Kaufman et al. [6] advocate immediate surgical exploration and removal of granulation with replacement of prosthesis. Seicshnaydre et al. [3] mentioned the use of high-dose steroids and antibiotics followed by delayed surgery. Hough and Dyer [11] considered surgery to be contra-indicated in such patients.

According to Fenton et al. [2] immediate exploration and meticulous removal of granulations followed by delayed ossiculoplasty if there is residual hearing is the appropriate line of management.

As in our case the lenticular process of incus was necrosed with minimal anterior displacement and the facial nerve was exposed, we decided to avoid putting a new piston during this surgery.

Since our patient has a normally functioning opposite ear, if she prefers, we plan to give her a hearing aid trial before going ahead with revision stapes surgery.

Even though there are no published papers specifically on the treatment of granulomas, several authors, based on their experience, have obtained better results by combining corticosteroids and early revision with removal of the granuloma and placement of a new prosthesis [3] [4].

\section{Conclusion}

Though rare is the post-stapedectomy/stapedectomy, granulations/reparative granuloma is an important cause of sensorineural hearing loss in operated cases of otosclerosis. Unfortunately, there aren't predictive patterns for its occurrence. We should be ready to deal with this situation if it arises in spite of its rarity.

\section{References}

[1] Harris, I. and Weiss, L. (1962) Granulomatous Complications of the Oval Window Fat Grafts. The Laryngoscope, 72, 870-885. http://dx.doi.org/10.1288/00005537-196207000-00003

[2] Fenton, J.E., Turner, J., Shirazi, A. and Fagan, P.A. (1996) Post-Stapedectomy Reparative Granuloma: A Misnomer. The Journal of Laryngology \& Otology, 110, 185-188. http://dx.doi.org/10.1017/S0022215100133134

[3] Seicshnaydre, M.A., Sismanis, A. and Hughes, G.B. (1994) Update of Reparative Granuloma: Survey of the American Otological Society and the American Neurotology Society. American Journal of Otology, 15, 155-160.

[4] Tange, R.A., Schimanski, G., van Lange, J.W., Grolman, W. and Zuur, L.C. (2002) Reparative Granuloma Seen in Cases of Gold Piston Implantation after Stapes Surgery for Otosclerosis. Auris Nasus Larynx, 29, 7-10. http://dx.doi.org/10.1016/S0385-8146(01)00106-7

[5] Burtner, D. and Goodman, M.L. (1974) Etiological Factors in Post-Stapedectomy Granulomas. Archives of Otolaryngology, 100, 171-173. http://dx.doi.org/10.1001/archotol.1974.00780040179003

[6] Kaufman, R.S. and Schuknecht, H.F. (1967) Reparative Granuloma Following Stapedectomy: A Clinical Entity. Annals of Otology, Rhinology \& Laryngology, 76, 1008-1017. http://dx.doi.org/10.1177/000348946707600511

[7] Scott-Brown (2008) Otosclerosis. In: Michael Gleeson Scott-Brown's Otorhinolaryngology, Head and Neck Surgery, 7th Edition, Hodder Arnold, London, 3477.

[8] Mann, W.J., Amedee, R.G., Fuerst, G. and Tabb, H.G. (1996) Hearing Loss as a Complication of Stapes Surgery. Otolaryngology —Head and Neck Surgery, 115, 324-328. http://dx.doi.org/10.1016/S0194-5998(96)70046-3

[9] Bellucci, R.J. and Wolff, D. (1960) Tissue Reaction Following Reconstruction of the Oval Window in Experimental Animals. Annals of Otology, Rhinology \& Laryngology, 69, 517-539. http://dx.doi.org/10.1177/000348946006900217

[10] Dawes, J.D.K., Cameron, D.S., Curry, A.R. and Rannie, I. (1973) Poststapedectomy Granuloma of the Oval Window. The Journal of Laryngology \& Otology, 87, 365-378. http://dx.doi.org/10.1017/S002221510007701X

[11] Hough, J.V.D. and Dyer, R.K. (1993) Stapedectomy, Causes of Failure and Revision Surgery in Otosclerosis. Otolaryngologic Clinics of North America, 26, 453-470. 